\title{
Practices and forms of open space at territorial scale: $A$ comparison between Matera and Valencia, two cities crossed by minerals rivers
}

\author{
Marialucia Camardelli', Maria Valeria Mininni', \\ Adolfo Vigil de Insausti
}

${ }^{1}$ Department of the European and Mediterranean Cultures (Architettura). Università degli Studi della Basilicata-DiCEM, Matera, Italy

${ }^{2}$ Escuela Técnica Superior de Arquitectura. Universitat Politècnica de Valencia, Valencia, Spain E-mail: camardelli.m@gmail.com, mariavaleria.mininni@unibas.it, advide@urb.upv.es

\begin{abstract}
A scientific reading of the transformations of Matera starting from the urban re-activation in a social and spatial perspective in its neighbourhoods. The redevelopment of urban voids starts by the metaphor of the ecological network in an urban scale to update the connection system of open spaces in the light of new practices and flows, for an innovative idea of urban resilience. The key role is re-see the neighbourhood: (i) on a local scale, focusing on the practices and customs, in the centre like in the industrial areas, starting processes of recovery and reuse but also of innovation (that result from the opportunity to be the European Capital of Culture 2019); (ii) on a urban scale with the transition space and threshold, identifying those natural and mineral signs representing a transition of porosity. The value of the "suburbs" enters as re-starting for rebirth of the city projects counting on the creativity of practices into the open spaces. The reformist project of Matera as original "laboratory" of architectural and urban experiments changes. Neighbourhoods were born from the same idea of "vicinato" (neighbour) but adapted to a new social identity, able to work on embryos of community, in the same way in Valencia in which natural elements (Turia) lead to rediscover the sense of belonging and making community. In both cases, urban policies are oriented towards innovative and spontaneous processes able to change the urban approach to a multi-purpose city although representative of culture and identity.
\end{abstract}

Keywords: Matera, Valencia, Neighbourhood, Urban regeneration, Requalification of urban voids.

\section{IIntroduction}

Valencia and Matera are cities crossed by mineral and natural rivers. On the one side, there are the third most populated city of Spain and, on the other side, there are a small town in southern Italy that has known for its unrepeatable urban shape, Sassi, which in the last few years, has been proclaimed European Capital of Culture 2019. The point of contact between Valencia and Matera is their ecological networks as multipurpose elements, generative metaphors of the city and interpreters of a non- osmosis system, although strongly evocative of a continuity of the urban green system.

In the following, we adopt, like system of reading, the presentation of the main characteristics of the individual cities, respectively Matera and Valencia, and then describe the analogies, derogations and, for a better comprehension, the confrontation. This comparison derives from the intrinsic condition of the two cities focusing on the conformation of space and practices that these spaces receive; all to favour the sliding systems (water, green, open spaces). 
For the city of Valencia, the configuration of space depends on the water but with the difference represented by a stiffening of the system, through the hydraulic transformations that led to the deviation of the Turia watercourse (Plan Sur). An important event influences Valencia's urban history: the flooding of 1957. In the same period, the city lives an accelerated growth of the population density. Demographic growth, if a right planning did not support it (providing to an increase of the infrastructure with the simultaneous design of public equipment) would have been problematic. The propose of redevelopment of the riverbed, the Plan Sur, initially was only an hydraulic project. Soon, however, the modifications, introduced in the urban structure, changes the layout of the city's general plan. In fact, the Plan General de Ordenación Urbana (general plan of the city - from there referred as the "PGOU") was adapted to Plan Sur and was defined a macroplan of road and hydraulic infrastructure.

The plane becomes radio-centric space model articulated for six radial routes and five circular ring, two of which are historic, the first above the ancient wall and the second for the transit. Two transverse elements complete this structure with the main road axes: one flanking the ancient Turia's riverbed, the other passing the beach of Malvarosa.

Certainly, the decade of the $60 \mathrm{~s}$, can be considered as that of the creation of the metropolitan area of Valencia. The process of change and transformation was double: the central city grows (developing as a service and coordination centre of the entire area) and present an evolution of other activities. In conclusion, this produced the consolidation of the metropolitan scheme with the consequential overturning of the first urban footprint.

For Matera, Sassi are a great "waterless" hydrographic system. The Piano Regolatore Generale, plan of the city by Luigi Piccinato (from now, for simplicity, indicated with the acronym "PRG" or "Piccinato Piano") consider the park system and the morphology of the territory, for the first time in 1956. The PRG is prepared on the initiative of the Ministry of Public Works with skeleton made up with four new districts built for the displacement of the Sassi, and the accomplishment of the rural villages provided in the "Piano generale di bonifica del territorio comunale di Matera" (masterplan for reconstruction of Matera municipal area).

Main assumption of Matera's plan is the progress of the quality of life of residents through revision, recovery and upgrading of: caravans and pedestrian infrastructures, provision of existing services, green areas with the realization of equipped public spaces and environmental recovery. In this new planning, there are the transformation of the space also based on the evolution of the inhabitants and the users of it. Green is not a geometric system, represented by the only planning of a regular grid (e.g. Bari or Barcelona), which identifies the expansion of the city, but through the study of the land morphology, following its natural course.

Starting from the forms described above, the work wants to explore the open space system of the two cities, comparing them as connections of nature streams and practices. This can help to redesign an ecological network (as a way to favour the connections of naturality in the city) between urban and extra urban, but also how to facilitate and improve social connection. It is not enough to linger on the ground surfaces present in the two cities, such as the Jardín de Turia for Valencia and Gravina (with its Murgia Materana Park) for Matera, but focus to the forms of space identifying into the voids the ideal-typical matrices of green, water and open space.

Green represents the element of conjunction of spaces, in all their form and size, inside the city centre, in the peri-urban and e nearby the agricultural area. It is watershed between different landscapes. However, this kind of spaces contains element that does not oppose resistance and that can be crossing creating seamless landscapes and ecological network. The space is not really stiffening up and the way to live them but calls for interactions with the creation of "new permeable squares".

Water is the element that connects and, in its natural conformations, changes geography and the way of living space (Plan Sur), creates new forms of aggregation or marks a limit (Gravina stream) to urban expansion and urban crossing. Overcoming this limit is an important 
opportunity for tourist development of the territory (Tibetan bridge).

In both cities, public space should not be understood as the simple residual of dense industrial urbanization. Neither it must be confined only to road fabric, to a few band spaces, to the edge of the urban fabric, but it should represent a constituent element of fringe of naturality. Therefore, it is necessary to look at it as a continuous, articulated and integrated system that develops from the scale of "vicinato" relations (neighbourhood) to the scale of large environmental systems. This helps to promote the spread of the enjoyability of public spaces to the whole community and to raise up the urban quality; also through their unusual and creative use, that offers a new and alternative city vision.

\section{Methodology}

The method is a comparison, in the urban design, of two cities, Valencia and Matera, between open spaces, urban texture and natural morphologies. The methodology approach is urban planning considering the space of practice.

For Valencia, we start from a historical and urban reconstruction where the processes that led to the evolution of the city were studied, focusing on the correlation between existing urban space and new forms of expansion.

Space value is important because it binds to the size of natural and anthropic flows. For this reason, starting from the comparison between full-empty in urban areas, we develop a taxonomy of urban texture, identifying permeable, semi-permeable and impermeable spaces.

The complexity of public spaces is evaluated in the intrinsic conditions of relationships, in quantities and traces due to flows of influence and, based on the results, is performed a grouping of spaces similar by form with different attitudes or not really appreciated for their quality, but referenced in the neighbourhoods.

Classification considers spaces grouped into: i) landscapes surface that reconfigure an urban area through the green; ii) proximity spaces that identify the public-private dimension in the city's spatial areas; iii) void-to-fill that suggests methodological proposals and possible lines of intervention; iv) regenerated spaces that identify rehabilitated areas but not completely solved because they are not the result of a participated urban planning;

We studied the "public city" through a conceptualization that was able to define character and set of common problems. The proposal consists in a reading of the open space and, from a visual analysis of the neighbourhoods, we see space dimensions, focusing on parameters such as size, distance and permeability.

The subdivision based on the size concerns the activities. Extra-Small or Small spaces are proximity spaces where activities doesn't exist; but this doesn't mean that the Medium or Large spaces are structured in a way to favour that because also that can have any significant critical issues.

The parameter distance between the various spaces leads to the consideration of neighbourhood relations in a way to link the activities that develop in them. This creates a network of spaces and underline the possible preferential routes. We shouldn't think that the transversal element, that marks the city, justifies the not-presence of small open spaces because, in each area, that kind are necessary to facilitate the creation of a system made of punctual elements.

Permeability parameter represents the texture of space in a gradient that expresses a percentage of the amount of impermeable, semi-permeable and permeable elements that rises to interpretive categories, which express the opportunities and the problems in function of their correct fruition.

Next stop is a depth study in which we can read the various returns of the idea of liveability of open space, through the study of some examples.

These spaces read the taxonomies, roles and performances to find a new connection between modern, contemporary and historic city; going beyond the intended uses, but considering suggestions that can better articulate the living conditions to live in the contemporaneity, the community, and the neighbourhood. 
For Matera, we made a similar work starting from an urban study and focusing on the role of the historic suburbs. The following study develops in several strictly connected and dependent phases. The first is a punctual relief of the existing, focusing on: settlement system, urban structure and open spaces (intended as soil quality).

Then there is a critical comparison phase with plan predictions through an analysis of what is planned and/or is implemented by urbanistic plans and projects on a peri-urban, urban and district scale (Carta Idrologica and Carta di uso del suolo contained in Piano Strutturale Comunale, Sistema del Verde e della Mobilità Lenta contained in Regolamento Urbanistico).

Following there is an investigation about open space practices choosing some significant and doing hearing and practice analysis to get a complete description helpful for the last phase of project imaginary.

The assumption of this logic is regeneration from which start with sustainable and equitable projects from environmental and social point of view. We try to use this study to improve the quality of open spaces through an operative ecological network. With it, the natural sign configures the city, following the fibre of the territory in a continuous rediscovery of elements that overcome the rigidity of urbanization in the light of habitability and comfort of open spaces.

\section{Measurement and analysis}

Starting from the method used, the results obtained share landscape relationships, new town planning choices, city forms and public space.

To build landscape relations and new urban planning choices, in a city like Valencia, the river becomes urban material losing its power of element of nature, to build landscape relationships and new town planning choices, and creating a crossroad that is represented by Jardin de Turia: green space, generating axes for the road map, vertebra and centre of the city. However, the creation of this element is not enough to provide for the requirements of other kind of spaces. An impressive range that evokes that of Matera neighbourhood. In fact, Matera from the Gravina to the Ecological Network, through the new "Sassi", is a city with a large amount of green peri-urban and urban, poorly connected to equipment that allow the slow circulation. Stream and Murgia can become places to cross, connections to the city, new urban rivers and green axes. Everything is to compensate the inefficiency of open spaces, which stop the concreting of the soil, taking advantage of these elements as an opportunity for development of green and slow mobility.

The city's forms for Matera and Valencia are the result of the correlation between the existing urban space and the new forms of expansion in a biunivocal correspondence that sees, on the one hand, the definition of new accumulation centres and, on the other, the consolidation of the historical town.

In the case of Valencia, the city evolved according to dependency criteria, specifically following ramification process that saw the explosion of new spaces. In fact, the city recorded an exponential urban growth, determined by the substantial industrial development, which had a significant impact on the subsequent evolution of the territory. In particular, in the last sixty years, Valencia grew significantly in a radial way, broadening itself almost spreading in all directions. The form the city is that we know today.

As regards, Matera's urban development follows the criteria of articulation according to a expansion for decentralized cores. The " Legge Speciale per lo sfollamento dei Sassi" (special law for the evacuation of Sassi's area) imposed at two-thirds of the inhabitants to leave their homes due to unhealthy conditions. A painful process, however, that led to the birth of new neighbourhoods designed by important architects (Ludovico Quaroni, Carlo Aymonino, Luigi Piccinato), making Matera an exclusive laboratory of architectural and urban experimentation. The new districts tell the story of a new city. Spine Bianche, La Martella, Serra Venerdì and Borgo Venusio give a new method of doing architecture making the city a field of sociological investigations, before, and planning proposals, then. The rebirth of the city result more evident with the conquest of the 
city Heritage Unesco Designation in 2009 that leads to the idea of "Matera, resilient cities" and those same spaces become an attempt to qualify urban voids.

In general, the shape of the city changes in the local and urban sphere, according to a contribution that, locally, sees neighbourhoods playing a key role, focusing on their practices and uses, and introducing processes of recovery, reuse and innovation derived from generational and anthropic transformation of the cities.

The open space of the public city, for Valencia and Matera, can sometimes appear inconvenient or a stand-alone system within the archipelago of settlements that constitute the contemporary urban void. The differentiation of contexts forces, however, to pay particular attention to the open space created by the modern city in the last century, which has changed its role, progressively, expanding and emerging, like choice consequent to the character private and public of independent building volumes. The public-private correlation generates the concave and convex interpretative categories seen as conceptual figures that help to rewrite the space from the redefinition of habitatsforms, helping to read the dimensions of interior and exterior as city conditions: emptyfull, urban margins-deep signs.

The empty one, for example, assumes value in relation to the full one as a connection between the urban parts. In other words, empty-space gains sense in how to relate to the full, defining the modes of use, times and frequencies that support it and hosting new practices.

Empty space, therefore, becomes a positive category of space, capable of helping the interpretation of the city over its public and semi-public parts. In the urban sphere, empty space establishes two modes of relationships: the space between the parcelling houses and the pertinence space of streets and public buildings, which is more open and porous. On an extra-urban scale, the empty gives to the city the opportunity to define land project through the theme of transition from city to countryside and urban borders to peri-urban space, elaborating the meaning of this passage through better planning of urban signs.

\section{Conclusion}

The public city is an opportunity to re-valuate the role of open space and the future scenarios of urban regeneration, on the one side as an inner resource, on the other side as a possible occasion of crossing and encounter by different urban populations.

These hypothetical future projects based on development of possible ecological networks that advantage natural and anthropic flows and give sense to the public space. For this reason, looking at the spaces that take part in the concave-convex comparison, they can be considered respectively like elements of the network: the primary connections (represented by the tree system and the ecological corridors) and the secondary ones (the stepping-stones that localize the passage from one system to another). The ecological network has the role of making the city more permeable (from green corridors, to natural migratory flows, to agricultural naturalness), but, above all, it shows the potential of population movement inside the open spaces and habitable greenery, creating flows of naturalness and actions that accentuate the identity of the spaces.

In view of an open space development, it's necessary enter in consonance with practices and their actions is essential to grasp the meaning, inside the friction between physical and social space, of the daily experience that has been lost with modernity and which represents the concept to which aim most of recent projects.

The way to rethink on spaces generates a series of strategies that lead to the consideration of public space as the one the inhabitant's experience. There are breakthrough strategies that create discontinuity elements in open space perimeters. These elements "break", with the punctual opening operations, the border between the public neighbourhood and the urban context. In other cases, there are reactivation strategies of transition space, by intensifying the use character through overlapping jobs or by temporarily adoption of spaces that do not cover a continuous cycle.

All this leads to say that open space does not only have a predominant identity, but in some cases, has the potential to make available 
spaces to occupation phenomena or "do-ityourself" practices that redefine relationships and possibility of use in the different ways of restitution of perceptual continuity or of crossing the open space.

To do this, it is necessary to take an investigation, sometimes subjective, focused to what there are in the area, to the equipment and to the traces that the social practices leave. All this, for the purpose to understanding the requests to give technically relevant answers and to define the possible innovative treatments.

\section{References}

Cremaschi M. (2008), Tracce di quartieri. Il legame sociale nella città che cambia. in Franco Angeli, Milan (ed) 'Narrazioni e cambiamento nei quartieri'.

Laureano P. (1993), Giardini di pietra. I Sassi di Matera e la civiltà mediterranea, in Bollati Boringhieri, Torino (ed.)

Bilò F. and Vadini E.(2016) 'Matera e Adriano Olivetti. Testimonianze su un'idea per il riscatto del Mezzogiorno', in Edizioni di Comunità, Rome (ed.).

Mininni M.(2015), "Nuove società e inerzia dello spazio aperto. Matera e gli esiti di un progetto riformista agro-urbano", in Territorio n.72, pp.59-66.

MATERA 2019, European Capital of Culture, Dossier (http://www.matera-basilicata2019. it/it/mt2019/dossier-di-candidatura.html). 